Implications for Rehabilitation

- Many people living with HIV do not comply with general health recommendations.

- Physical activity counselling should be key in the rehabilitation of people living with HIV.

7

10

11

12

13

14

15

16

17

18

19

20

21

22

23

24

25

26

27

28

29

30

31

32

33

34

35

36

37

38

39

40

41

42

43

44

45

46

47

48

49

50

51

52

53

54

55

56

57

58

59

60 


\title{
Global Physical Activity Levels Among People Living with HIV: A Systematic Review and Meta- analysis
}

\author{
Davy Vancampfort ${ }^{\mathrm{a}, \mathrm{b},{ }^{*}}$, James Mugisha ${ }^{\mathrm{c}, \mathrm{d}}$, Marc De Hert ${ }^{\mathrm{b}}$, Michel Probst ${ }^{\mathrm{a}}$, Joseph Firth ${ }^{\mathrm{e}}$, Paul \\ Gorczynski ${ }^{\dagger}$, Brendon Stubbs ${ }^{g, h}$ \\ ${ }^{a}$ KU Leuven - University of Leuven, Department of Rehabilitation Sciences, Leuven, Belgium \\ ${ }^{b} \mathrm{KU}$ Leuven - University of Leuven, University Psychiatric Center KU Leuven, Leuven-Kortenberg, \\ Belgium \\ ${ }^{c}$ Butabika National Referral and Mental Health Hospital, Kampala, Uganda \\ dKyambogo University, Kampala, Uganda \\ ${ }^{\mathrm{e}}$ Institute of Brain, Behaviour and Mental Health, University of Manchester, Manchester, UK \\ 'Department of Sport and Exercise Science, University of Portsmouth, Portsmouth, Hampshire , UK \\ ${ }^{9}$ Physiotherapy Department, South London and Maudsley NHS Foundation Trust, London, UK

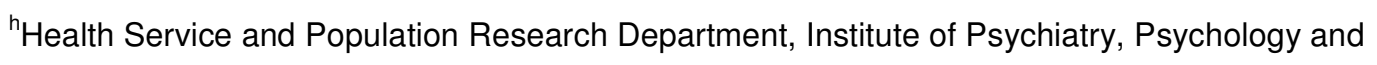 \\ Neuroscience, King's College London, De Crespigny Park, London, UK
}

Running Head: Physical Activity Levels in HIV

*Corresponding author. Leuvensesteenweg 517, B-3070 Kortenberg, Belgium. Tel.: +32 275805 11;

Fax: +32 2759 9879. E-mail address: Davy.Vancampfort@uc-kortenberg.be 


\section{Abstract}

Purpose: It is unclear how much physical activity people living with HIV (PLWH) engage in. We conducted a meta-analysis to investigate physical activity levels and its predictors in PLWH.

Methods: PubMed, PsycARTICLES and CINAHL Plus were searched by 2 independent reviewers from inception till April $1^{\text {st }} 2016$ using the keywords: 'HIV' OR 'AIDS' AND 'physical activity' OR 'exercise' OR 'sports'. A random effects meta-analysis was conducted.

Results: Across 24 studies including 34 physical activity levels there were $3,780(2,471$ औ) PLWH (mean age range: $37-58$ years). PLWH spent $98.9(95 \% \mathrm{Cl}=64.8-133.1)$ minutes per day being physically active which is lower than in most other populations with chronic diseases. $50.7 \%$ $(95 \% \mathrm{Cl}=39.3-62 \%)(\mathrm{n}=2,052)$ of PLWH complied with the physical activity guidelines of $150 \mathrm{~min}$ moderate intensity physical activity per week. The number of steps walked per day in 252 PLWH was $5899(95 \% \mathrm{Cl}=5678-6418)$, which is below the 10,000 steps per day recommendation.

Conclusions: Our data demonstrate that a considerable proportion of PLWH are insufficiently physically active. Future lifestyle interventions specifically targeting the prevention of physical inactivity in PLWH are warranted.

Keywords: Exercise; Physical Activity; HIV; AIDS 


\section{Introduction}

People living with HIV (PLWH) have higher levels of morbidity and mortality than the general population. The non-AIDS related mortality rates are largely attributable to cardiovascular disease [1]. In the general population there is evidence that physical activity and exercise are broadly as effective as pharmacological interventions in preventing cardiovascular disease and premature mortality [2]. In the last decade, several systematic reviews and/or meta-analyses [3-8] have considered physical activity as a therapeutic intervention concluding that it improves the body composition, muscle strength, aerobic fitness, and quality of life.

Despite the benefits of an active lifestyle, PLWH experience a range of barriers towards engaging in physical activity, such as side-effects of antiviral therapy, depression, bodily pain, and the presence of opportunistic infections [9]. Facilitators of physical activity include a higher cardiorespiratory fitness level, a higher self-efficacy, perceived benefits and greater motivation towards health improvement [9]. Given that an active lifestyle is related to lower cardiovascular disease risk, understanding physical activity levels among PLWH is critical to improving long-term health outcomes [10].

Moreover, several important questions regarding the relationship between physical activity and HIV/AIDS remain unanswered. For instance, the exact levels of physical activity among PLWH has yet to be established. A systematic review of Schuelter-Trevisol and colleagues in 2012 indicated that there was too much heterogeneity in physical activity assessment and too limited data were available to make any firm conclusions [11]. It might be hypothesized that since 2012 a considerable number of papers have been published on physical activity levels in PLWH.

Along with obtaining an accurate estimate of the levels of PA among PLWH, understanding predictors of PA in this patient group is also of relevance for improving clinical practice, while providing a platform for future research endeavors. Next to this, it is of interest to explore whether geographical differences and differences between settings (e.g., outpatients, inpatients and community patients) in physical activity exist, as such differences might help researchers and clinicians to identify specific environmental factors (e.g. differences in health-related policies, available facilities, other lifestyle factors etc.) which may influence PA. Demographical predictors (age, gender, ethnicity, presence of co-morbidity, etc.) may also identify those at a higher risk for lower physical activity participation. In 
1

2

3

4

5

6

7

8

9

10

11

12

13

14

15

16

17

18

19

20

21

22

23

24

25

26

27

28

29

30

31

32

33

34

35

36

37

38

39

40

41

42

43

44

45

46

47

48

49

50

51

52

53

54

55

56

57

58

59

60

addition, it remains unclear if PLWH engage in more or less physical activity compared to the healthy population.

In order to address the current gaps in the literature, the primary aims of this systematic review and meta-analysis were to establish: (a) the pooled mean time spent physically active (light, moderate and vigorous and total physical activity, and number of steps per day), (b) the pooled percentage of people assigned to the low, moderate or highly physically active groups as defined by the widely used International Physical Activity Questionnaire (IPAQ)[12], (c) the pooled percentage of people complying with the general health recommendation of at least 150 min of moderate intensity physical activity per week, and (d) the pooled physical activity levels expressed as metabolic equivalent (MET) minutes per week taking into account established MET values for each activity level (i.e., walking: 3.3; moderate: 4.0; vigorous: 8.0 ). The secondary aims were to investigate predictors of physical activity using meta-regression analyses, and to explore differences in physical activity in PLWH versus the healthy population. 


\section{Methods}

This systematic review adhered to the MOOSE guidelines [13] and PRISMA statement [14].

\section{Inclusion Criteria}

We included studies that: (a) involved only adult participants ( $\geq 18$ years) with a diagnosis of HIV/AIDS. (b) Measured physical activity using either a subjective questionnaire (e.g. International Physical Activity Questionnaire (IPAQ)[12]) or objective measure (e.g. accelerometer). Physical activity was defined as any interventions that use bodily movement produced by skeletal muscles and which requires energy expenditure[15]. (c) Were interventional (randomized controlled trials (RCTs), clinical controlled trials (CCTs)) or observational (prospective or cross-sectional) studies conducted in any setting (inpatients or outpatients). For prospective and interventional studies only the baseline data were included. (d) Were published in an international peer-reviewed journal.

\section{Exclusion Criteria}

Exclusion criteria were: (a) non-quantitative studies, (b) not including PLWH, and (c) no adequate measure of physical activity (see outcomes), (d) studies limited to or excluding PLWH with chronic comorbidities (e.g. cardiovascular diseases, cancer, liver diseases, etc.), and (e) studies limited to drug users.

\section{Search Strategy}

Two independent authors (DV and BS) searched PubMed, PsycARTICLES and CINAHL Plus without language restrictions from inception till April $1^{\text {st }}$ 2016, using the keywords: 'HIV' OR 'AIDS' AND 'physical activity' OR 'exercise' OR 'sports'. In addition, reference lists of all eligible articles and related systematic reviews were screened to identify potentially eligible articles.

\section{Study Selection}


After removal of duplicates, two independent reviewers (DV and BS) screened titles and abstracts of all potentially eligible articles and a final list of included articles was reached through consensus. A third reviewer (JM) was available for mediation throughout this process.

\section{Outcomes}

The primary outcome was the mean time (minutes) per day that PLWH engaged in physical activity. We collected separate data for light, moderate and vigorous intensity and total physical activity if these data were reported. Next to this, the percentage of people assigned to the low, moderate or highly physically active groups as defined by the widely used International Physical Activity Questionnaire [12] were pooled. Extracted as well were the percentage of people complying with the general health recommendation of at least $150 \mathrm{~min}$ of moderate intensity physical activity per week and physical activity levels expressed as metabolic equivalent (MET) minutes per week taking into account established MET values for each activity level (i.e., walking: 3.3; moderate: 4.0; vigorous: 8.0). Finally, we also collected data on physical activity behavior among healthy controls (where reported).

\section{Data Extraction}

One author (DV) extracted data using a predetermined data extraction form, which was subsequently validated by a second author (BS). The data extracted included first author, geographical region, setting, participants included in the article (including mean age, \% male, \% White, \% employed, mean HIV duration, mean body mass index, mean oxygen uptake, mean CD4+ count, mean HIV viral load, $\%$ with diabetes, \% smoking), physical activity assessment method (objective or self-report), and the primary outcomes.

\section{Meta-analysis}

Due to the anticipated heterogeneity across studies, we conducted a random effects meta-analysis with Comprehensive Meta-Analysis software (CMA, Version 3). The meta-analysis was conducted in the following sequence. First, we calculated the mean amount of time (total and at light, moderate and high intensity) and median total time spent in physical activity per day together with the $95 \%$ confidence intervals $(\mathrm{Cl})$. Second, we calculated pooled percentage of people assigned to the low, moderate or highly physically active groups and the percentage of people complying with the general 
health recommendations and physical activity levels expressed as metabolic equivalent MET minutes per week and where possible, also according to the measurement (self-report versus objective measurement). Third, we investigated potential moderators of physical activity behavior in PLWH with meta-regression analyses. The potential moderators of interest were geographical location (NorthAmerica, South-America, Africa, Asia, Europe, Australia), setting (inpatients, outpatients, community patients, mixed settings), mean age (years), \% male, \% White, \% employed, mean HIV duration (years), mean body mass index $\left(\mathrm{kg} / \mathrm{m}^{2}\right)$, mean oxygen uptake $(\mathrm{ml} / \mathrm{min} / \mathrm{kg})$, mean CD4+ count (cells $/ \mathrm{mm}^{3}$ ), mean HIV viral load (log 10 copies $/ \mathrm{mL}$ ), \% with diabetes, \% smoking), and physical activity assessment method (objective vs self-report). Fourth, we conducted a comparative metaanalysis investigating differences in physical activity levels with healthy controls calculating Hedges' $g$ and the $95 \% \mathrm{Cl}$ as the effect size. In addition, we calculated the mean difference in minutes per day together with the $95 \% \mathrm{Cl}$ in levels of physical activity behavior. Heterogeneity was assessed with the $\mathrm{I}^{2}$ statistics for each analysis [16]. Publication bias was assessed with the Begg-Mazumdar Kendall's tau [17]. For all analyses we calculated the trim and fill adjusted analysis [18] to remove the most extreme small studies from the positive side of the funnel plot, and recalculated the effect size at each iteration, until the funnel plot was symmetric about the (new) effect size. 


\section{Results \\ Search Results}

The initial search yielded 13,340 results. After removal of duplicates and exclusion at the title/ abstract level, 74 abstracts were retrieved in full. At the full text review stage, 64 articles were considered and 40 were subsequently excluded (see figure 1 for search results). Full details of the 24 [19-42] included studies are summarized in table 1.

Insert figure 1 about here

\section{Study and Participants' Characteristics}

Except for one randomized controlled trial [28], all studies were cross-sectional. Ten studies reported physical activity levels for 2 subgroups, e.g. for men and women separately. Across the 24 unique studies, including 34 physical activity levels, there were $3,780\left(2,471{ }^{\lambda}\right) \mathrm{PLWH}$. The mean age ranged from 37 to 58 years. The sample size ranged from 10 to 628 . Fifteen physical activity levels were assessed in North-America, 6 in South-America, 6 in Africa, 3 in Europe, 2 in Asia (China) and 2 in Australia. Sixteen physical activity levels were assessed in an outpatient setting, 2 in an inpatient setting, and 14 in a community setting. Of studies reporting data, the \% of White ethnicity ranged from 0 to $91.9 \%(\mathrm{~N}=8)$, the mean body mass index $(\mathrm{BMI})$ from 22.9 to $36.6(\mathrm{~N}=16)$, the cardiorespiratory fitness (maximal oxygen uptake) from 26.8 to $34.2 \mathrm{l} / \mathrm{min} / \mathrm{kg}(\mathrm{N}=3)$, the $\mathrm{CD} 4+$ count from 256 to 597 cells $/ \mathrm{mm}^{3}(\mathrm{~N}=18)$, the viral load from 1.6 to $4.4 \log 10 \mathrm{copies} / \mathrm{mL}(\mathrm{N}=6)$, the HIV duration from 3.9 to 18.0 years $(\mathrm{N}=13)$, the $\%$ of people with diabetes from $0 \%$ to $26 \%(\mathrm{~N}=8)$, and the $\%$ of people smoking from $0 \%$ to $66 \%(\mathrm{~N}=13)$. Three studies reported general population control data. In total $695(663 \hat{)})$ PLWH (mean age $=47.5$ years) were compared with $773\left(743{ }^{\lambda}\right)$ age- and gender matched controls (mean age $=49.9$ years). Demographical and clinical data of the 24 studies including 34 physical activity levels are summarized in table 1, physical activity outcomes in table 2.

Insert table 1 about here

Insert table 2 about here 


\section{Meta-analysis of the Time Spent Physically Active}

Results of the meta-analyses are summarized below. Full details are presented in table 3 . Three studies $[39,40,42]$ including 4 physical activity levels reported the total time spent physically active across $144 \mathrm{PLWH}$. The total time spent physically active was $98.9(95 \% \mathrm{Cl}=64.8-133.1)$ minutes per day (after trim-and-fill adjustment). When looking at the different physical activity intensities, only 1 study ( $n=65)$ [34] provided data on the time spent in vigorous physical activity, reporting a mean of $10 \pm 1$ minutes of vigorous PA per day in PLWH. Three studies $[24,26,34]$ including 4 physical activity levels $(n=171)$ found that PLWH engaged in a mean of 61.7 minutes per day $(95 \% \mathrm{Cl}=48.8-74.7)$ (after trim-and-fill adjustment) of moderate intensity physical activity. Also 3 studies ( $n=108)$ provided data on the time spent in light physical activity. Two studies $[34,37]$ including 3 physical activity levels $(n=95)$ showed that PLWH spent a mean of $72.8(95 \% \mathrm{Cl}=34.9-110.7)$ minutes per day in light physical activity. Trim- and fill adjustment did not affect the estimate for light physical activity.

Insert table 3 about here

\section{Meta-analysis of the Number of Steps per Day}

Four studies $[19,26,28,36]$ including 7 physical activity levels reported the total number of steps walked per day in 202 PLWH (see Table 2). The trim-and fill adjusted number of steps per day was $5899(95 \% \mathrm{Cl}=5678-6418)$.

\section{Subgroup Analyses}

Due to limited data, only geographical differences could be explored in subgroup analyses.Table 3 shows that the number of steps walked per day in North-American studies was not significantly different than in European studies $(P=0.49)$.

\section{Meta-regression Analyses}

Separate single meta-regression analyses (see table 4) revealed that the number of steps walked per day was not moderated by gender (\% male), body mass index and \% of people with diabetes. In contrast, older age moderated a lower number of steps walked per day $(\beta=-66.7$, standard error $\left.(\mathrm{SE})=34.1, \mathrm{p}=0.049 ; \mathrm{r}^{2}=0.57\right)$. 
Meta-analysis of the \% of People Assigned to the Low, Moderate or Highly Physically Active IPAQ Groups

In total 5 studies [21-24,35] including 6 physical activity levels and involving 1,187 PLWH assigned participants to a category following the IPAQ recommendations: $31.9 \%(95 \% \mathrm{Cl}=24.9-39.7 \%)$ was assigned to the 'low physical activity' category, $33 \%(95 \% \mathrm{Cl}=26.2-40.7 \%)$ to the 'moderately physically active' category and $32.9 \%(95 \% \mathrm{Cl}=23.4-44.0 \%)$ to the 'highly physically active' category.

\section{Subgroup Analyses}

As can be noticed in Table 3, there were significant geographical differences, as well as significant differences between settings. Globally, more patients were assigned to the lower IPAQ category $(P<0.001)$ and less to the highly physically active IPAQ category $(P<0.001)$ in South-American participants, while significantly more community patients were assigned to the highly physically active IPAQ category compared with outpatients $(\mathrm{P}<0.001)$.

\section{Meta-regression Analyses}

Separate single meta-regression analyses revealed that assignment to any IPAQ category was not moderated by gender (\% male) and ethnicity (\% White). In contrast, a higher mean age at study level moderated a lower assignment percentage to the moderately physically active group $(\beta=-0.05$, standard error $\left.(S E)=0.01, p<0.001 ; r^{2}=1.0\right)$. There was a trend-level association for older age with lower assignment percentage to the highly physically active group $(\beta=0.05$, standard error $(S E)=0.03$, $\left.\mathrm{p}=0.054 ; \mathrm{r}^{2}=0.35\right)$.

\section{Meta-analysis of the Physical Activity Levels Expressed as Metabolic Equivalent (MET) Minutes per Week}

There were insufficient data to pool and meta-analyze the data $(\mathrm{N}=1)$. The mean MET minutes per week was 1666.0 . 
Meta-analysis of the \% of People Complying with the Guidelines

Within 9 studies [7,20,29-32,34,38,41] including 13 physical activity levels and involving 2,052 PLWH, $50.7 \%(95 \% \mathrm{Cl}=39.3-62 \%)$ complied with the physical activity guidelines by achieving $\geq 150$ minutes of activity per week.

Subgroup Analyses

There was no difference in compliance with PA guidelines between different settings, geographical regions and assessment methods. Details can be found in table 3.

Meta-regression Analyses

Separate single meta-regression analyses revealed that age, gender and physical activity assessment method did not moderate the percentage of people adhering to the physical activity guidelines (see table 4).

\section{Differences with Age- and Gender Matched General Population Controls}

There were insufficient data to explore differences in physical activity behavior between PLWH and controls. 


\section{Discussion}

\section{General Findings}

The current study is, to our knowledge, the first to meta-analyze physical activity levels and its predictors in PLWH. We found that PLWH spent 98.9 (95\% $\mathrm{Cl}=64.8-133.1)$ minutes per day being physically active. When looking at the different physical activity intensities, PLWH spent a mean of $72.8(95 \% \mathrm{Cl}=34.9-110.7)$ minutes per day in light physical activity, $61(95 \% \mathrm{Cl}=47.1-76.0)$ minutes per day in moderate intensity and 12.4 minutes per day in vigorous physical activity. Due to lack of data, we were not able to compare these levels with age- and gender matched healthy controls. However, previous similar meta-analyses in other vulnerable populations demonstrated higher (or similar) levels of physical activity. For example, a meta-analysis [43] of 6 studies involving $279\left(129{ }^{\lambda}\right)$ people with bipolar disorder (mean age=43.9 years; range: 32.0-51.5 years) demonstrated that people with established bipolar disorder spent in total $210.1 \mathrm{~min}(95 \% \mathrm{Cl}=146.3$ to $273.9 \mathrm{~min})$ per day being physically active. In another meta-analysis[44] of 35 studies representing 3,453 individuals with established schizophrenia (40.0 years; $64.0 \%$ male), engagement in light physical activity was 80.44 minutes, in moderate-vigorous physical activity 47.1 minutes and in vigorous physical activity 2 minutes per day. Our meta-analysis also showed that around half, i.e. $50.7 \%(95 \% \mathrm{Cl}=39.3-62 \%)$ of PLWH are complying with the physical activity guidelines of at least $150 \mathrm{~min}$ of moderate physical activity per week. When looking at the number of steps per day, PLWH walk $5798(95 \% \mathrm{Cl}=5640-$ 6212) steps which is below the general health recommendation of 10,000 [45].

Knowledge about predictors of physical activity levels helps identifying high-risk persons in whom physical activity participation is reduced, and therefore may require more intense and targeted interventions. Our data indicate, albeit inconsistently, that across the different physical activity outcomes there are geographical differences. More research is however needed to clarify these differences and for example the role of different health policies on the level of physical activity in PLWH between different countries. Also differences between settings were inconsistent. The percentage of people assigned to the highly physically active IPAQ group was higher in community versus outpatients. A possible reason might be that outpatients might have more severe physical or 
psychiatric co-morbidities than community patients (who are not necessarily currently connected with a care setting). The lack of differences with inpatients might be due to the inclusion of physical activity interventions in the multidisciplinary inpatient care [46]. Meta-regression analyses demonstrated that a higher mean age at study level predicted lower levels of physical activity (e.g., number of steps per day), a relationship also seen in the general population [47]. These data point towards the need of considering in particular the lower levels of physical activity in older people with HIV. A previous 12month randomized study of an education and home-based pedometer walking program in 84 older PLWH [28] demonstrated that such a program improves physical activity levels, and reduces the presence and severity of cardiovascular risk factors. For example, compared with controls, those in the walking intervention had better 6-minute walk test distance score $(P=0.01)$, a more beneficial waist to hip ratio $(P<0.001)$, lower blood glucose $(P=0.001)$, and higher high-density lipoprotein $(P=0.01)$ levels over the 12-month period.

There were too limited data to explore whether moderate to vigorous physical activity as assessed by objective measures differed with self-report measures. Future research should explore whether the current physical activity questionnaires do accurately collate data on physical activity behavior in PLWH or whether they over- or underestimate physical activity participation in this at risk group. It might be hypothesized that cognitive deficits associated with PLWH may for example lead to recall bias and for example an overestimation within self-report measures. Since the introduction of combination antiretroviral therapy, the incidence of severe forms of HIV-associated neurocognitive impairment has declined significantly [29]. However, the prevalence of the milder forms which might influence recall of physical activity behaviors has increased [48]. Also, significant psychological distress and depression, which are more prevalent among PLWH [49], may influence the ability to accurately respond to self-report questionnaires.

\section{Limitations}

Several limitations of this meta-analysis should be noted. Firstly, half of the included studies relied on data drawn from subjective rather than from objective assessment methods. Secondly, in the main analyses, we encountered high levels of heterogeneity. Whilst such heterogeneity is expected when combining observational data, this is a consideration when these main analyses are reviewed in isolation. However, we follow the MOOSE guidelines [13] to address this heterogeneity and we are 
able to explain large portions of the heterogeneity with our subgroup and meta-regression analyses. In particular, it appears that age among participants explained over half of the heterogeneity observed $\left(R^{2}=0.57\right)$. Third, due to the relative paucity of data, some of the subgroup analyses (e.g., IPAQ categories) had relatively low numbers of studies. Therefore, some caution should be attached to such results and clearly future research is required to better understand such relationships. It is also important that future research should seek to investigate physical activity behavior in this vulnerable population compared with well-matched (age, gender and BMI) healthy controls. Finally, there was inadequate information on other lifestyle factors (such as smoking), side effects of antiviral therapy, immunity parameters and physical and psychiatric co-morbidities, thus precluding rigorous metaanalytical or meta-regression analyses. Future research is required to understand the impact of these clinical parameters on physical activity behavior in this population. Nevertheless, allowing for these caveats, the results provide important information for clinicians and researchers.

In conclusion, our data show that a considerable proportion of PLWH are insufficiently

physically active. Given that physical activity is an independent predictor of cardiovascular disease (a major contributing factor towards premature mortality in PLWH), future lifestyle interventions specifically targeting the prevention of physical inactivity in PLWH are warranted.

\section{Funding}

None.

\section{Conflict of Interest}

Dr. Vancampfort has received research funding from Research Foundation - Flanders (FWOVlaanderen). Prof. Dr. De Hert reports being a paid consultant for, receiving grant or research support and honoraria from, and serving on the speakers' bureaus or advisory boards of Janssen-Cilag, Lundbeck, and Takeda. The other authors declare that they have no conflicts of interest to report. 


\section{References}

[1] Farahani M, Mulinder H, Farahani A, Marlink R. Prevalence and distribution of non-AIDS causes of death among HIV-infected individuals receiving antiretroviral therapy: a systematic review and meta-analysis. International journal of STD \& AIDS 2016:0956462416632428.

[2] Naci $\mathrm{H}$, loannidis JP. Comparative effectiveness of exercise and drug interventions on mortality outcomes: metaepidemiological study. BMJ 2013;347:f5577.

[3] Leach L, Bassett S, Smithdorf G, Andrews B, Travill A. Suppl 1: M3: A Systematic Review of the Effects of Exercise Interventions on Body Composition in HIV+ Adults. The Open AIDS journal 2015;9:66

[4] Neto MG, Conceição CS, Carvalho VO, Brites C. Effects of Combined Aerobic and Resistance Exercise on Exercise Capacity, Muscle Strength and Quality of Life in HIV-Infected Patients: A Systematic Review and Meta-Analysis. PloS One 2015;10:e0138066.

[5] Gomes-Neto M, Conceicao CS, Carvalho VO, Brites C. A systematic review of the effects of different types of therapeutic exercise on physiologic and functional measurements in patients with HIV/AIDS. Clinics 2013;68:1157-67.

[6] Gomes Neto M, Ogalha C, Andrade AM, Brites C. A systematic review of effects of concurrent strength and endurance training on the health-related quality of life and cardiopulmonary status in patients with HIV/AIDS. BioMed Research International 2013;2013.

[7] Fillipas S, Cherry C, Cicuttini F, Smirneos L, Holland A. The effects of exercise training on metabolic and morphological outcomes for people living with HIV: a systematic review of randomised controlled trials. HIV Clinical Trials 2010;11:270-82.

[8] O'Brien K, Tynan A-M, Nixon S, Glazier R. Effects of progressive resistive exercise in adults living with HIV/AIDS: systematic review and meta-analysis of randomized trials. AIDS Care 2008;20:631-53.

[9] Vancampfort D, Mugisha J, Richards J, Hert MD, Probst M, Stubbs B. Physical activity correlates in people living with HIV: a systematic review of 44 studies Submitted 2016. 
[10] Ward MC, White DT, Druss BG. A meta-review of lifestyle interventions for cardiovascular risk factors in the general medical population: lessons for individuals with serious mental illness. The Journal of Clinical Psychiatry 2015;76:e477-86.

[11] Schuelter-Trevisol F, H Wolff F, R Alencastro P, Grigoletti S, L Ikeda M, BM Brandao A, T Barcellos N, C Fuchs S. Physical activity: do patients infected with HIV practice? How much? A systematic review. Current HIV Research 2012;10:487-97.

[12] Craig C, Marshall A, Sjostrom M, Bauman A, Booth M, Ainsworth B, Pratt M, Ekelund U, Yngve A, Sallis $\mathrm{J}$ and others. International physical activity questionnaire: 12-country reliability and validity. Medicine \& Science in Sports \& Exercise 2003;35:1381-95.

[13] Stroup DF, Berlin JA, Morton SC, Olkin I, Williamson GD, Rennie D, Moher D, Becker BJ, Sipe TA, Thacker SB. Meta-analysis of observational studies in epidemiology: a proposal for reporting. JAMA 2000;283:2008-12.

[14] Moher D, Liberati A, Tetzlaff J, Altman DG. Preferred Reporting Items for Systematic Reviews and Meta-Analyses: The PRISMA Statement. PLoS Medicine 2009;6:e1000097.

[15] Caspersen CJ, Powell KE, Christenson GM. Physical activity, exercise, and physical fitness: definitions and distinctions for health-related research. Public Health Reports 1985;100:126.

[16] Higgins J. Cochrane Handbook for Systematic Reviews of Interventions. Version 5.1. 0 . The Cochrane Collaboration. 2011.

[17] Begg CB, Mazumdar M. Operating characteristics of a rank correlation test for publication bias. Biometrics 1994:1088-101.

[18] Duval S, Tweedie R. Trim and fill: a simple funnel-plot-based method of testing and adjusting for publication bias in meta-analysis. Biometrics 2000;56:455-63.

[19] Rehm K, D K-P. Physical activity levels and perceived benefits and barriers to physical activity in HIV-infected women living in the deep south of the United States. AIDS Care 2016.

[20] Dirajlal-Fargo S, Webel AR, Longenecker CT, Kinley B, Labbato D, Sattar A, McComsey GA. The effect of physical activity on cardiometabolic health and inflammation in treated HIV infection. Antiviral Therapy 2015.

[21] Fazeli PL, Marquine MJ, Dufour C, Henry BL, Montoya J, Gouaux B, Moore RC, Letendre SL, Woods SP, Grant I. Physical activity is associated with better neurocognitive and everyday functioning among older adults with HIV disease. AIDS and Behavior 2015;19:1470-7. 
[22] Monroe AK, Brown TT, Cox C, Reynolds SM, Wiley DJ, Palella FJ, Kingsley LA, Plankey MW. Physical Activity and Its Association with Insulin Resistance in Multicenter AIDS Cohort Study Men. AIDS Research and Human Retroviruses 2015;31:1250-6.

[23] Hsieh E, Fraenkel L, Bradley EH, Xia W, Insogna KL, Cui Q, Li K, Li T. Osteoporosis knowledge, self-efficacy, and health beliefs among Chinese individuals with HIV. Archives of Osteoporosis 2014;9:1-10.

[24] Della Justina LB, Luiz MC, Maurici R, Schuelter-Trevisol F. Prevalence and factors associated with lipodystrophy in AIDS patients. Revista da Sociedade Brasileira de Medicina Tropical 2014;47:30-7.

[25] Jaggers JR, Prasad VK, Dudgeon WD, Blair SN, Sui X, Burgess S, Hand GA. Associations between physical activity and sedentary time on components of metabolic syndrome among adults with HIV. AIDS Care 2014;26:1387-92.

[26] Ramírez-Marrero FA, Santana-Bagur JL, Joyner MJ, Rodríguez-Zayas J, Frontera W. Metabolic syndrome in relation to cardiorespiratory fitness, active and sedentary behavior in HIV+ Hispanics with and without lipodystrophy: fitness and metabolic-syndrome in HIV. Puerto Rico Health Sciences Journal 2014;33:163.

[27] Raso V, Shephard RJ, Casseb J, Duarte AJdS, Silva PRS, Greve JMDA. Association between muscle strength and the cardiopulmonary status of individuals living with HIV/AIDS. Clinics 2013;68:359-64.

[28] Roos R, Myezwa $H$, van Aswegen $H$, Musenge E. Effects of an education and home-based pedometer walking program on ischemic heart disease risk factors in people infected with HIV: a randomized trial. JAIDS Journal of Acquired Immune Deficiency Syndromes 2014;67:26876.

[29] Edward AO, Oladayo AA, Omolola AS, Adetiloye AA, Adedayo PA. Prevalence of traditional cardiovascular risk factors and evaluation of cardiovascular risk using three risk equations in Nigerians living with human immunodeficiency virus. North American Journal of Medical Sciences 2013;5:680.

[30] Segatto AFM, Freitas Junior IF, Santos VRd, Alves KCP, Barbosa DA, Portelinha Filho AM, Monteiro HL. Lipodystrophy in HIV/AIDS patients with different levels of physical activity while on antiretroviral therapy. Revista da Sociedade Brasileira de Medicina Tropical 2011;44:420-4. 
[31] Muronya W, Sanga E, Talama G, Kumwenda JJ, van Oosterhout JJ. Cardiovascular risk factors in adult Malawians on long-term antiretroviral therapy. Transactions of the Royal Society of Tropical Medicine and Hygiene 2011;105:644-9.

[32] Schuelter-Trevisol F, Fuchs S. Association between physical activity and lipodystrophy syndrome in patients with HIV/AIDS. Porto Alegre: Universidade Federal do Rio Grande do Sul;87.

[33] Fillipas S, Cicuttini F, Holland AE, Cherry CL. The international physical activity questionnaire overestimates moderate and vigorous physical activity in HIV-infected individuals compared with accelerometry. Journal of the Association of Nurses in AIDS Care 2010;21:173-81.

[34] Allard JP, Arendt BM, Aghdassi E, Mohammed SS, Fung LY, Jalali P, Salit IE. Dietary intake and physical activity in a Canadian population sample of male patients with HIV infection and metabolic abnormalities. Current HIV Research 2008;6:82-90.

[35] Fillipas S, Bowtell-Harris C, Oldmeadow LB, Cicuttini F, Holland AE, Cherry CL. Physical activity uptake in patients with HIV: who does how much? International journal of STD \& AIDS 2008;19:514-8.

[36] Ramírez-Marrero FA, Rivera-Brown AM, Nazario CM, Rodríguez-Orengo JF, Smit E, Smith BA. Self-reported physical activity in Hispanic adults living with HIV: comparison with accelerometer and pedometer. Journal of the Association of Nurses in AIDS Care 2008;19:283-94.

[37] Sutinen J, Yki-Järvinen H. Increased resting energy expenditure, fat oxidation, and food intake in patients with highly active antiretroviral therapy-associated lipodystrophy. American Journal of Physiology-Endocrinology and Metabolism 2007;292:E687-E92.

[38] de Lima Eidam C, da Silva Lopes A, Guimarães MDC, Oliveira OV. Lifestyle of HIV seropositives patients and your association with CD4 positive t-lymphocytes counts. Brazilian Journal of Kinanthropometry and Human Performance 2006;8:51-7.

[39] Bopp CM, Phillips KD, Fulk LJ, Dudgeon WD, Sowell R, Hand GA. Physical activity and immunity in HIV-infected individuals. AIDS Care 2004;16:387-93.

[40] Ramírez-Marrero FA, Smith BA, Meléndez-Brau N, Santana-Bagur JL. Physical and leisure activity, body composition, and life satisfaction in HIV-positive Hispanics in Puerto Rico. Journal of the Association of Nurses in AIDS Care 2004;15:68-77. 
[41] Clingerman EM. Participation in physical activity by persons living with HIV disease. Journal of the Association of Nurses in AIDS Care 2003;14:59-70.

[42] Paton N, Elia M, Jebb S, Jennings G, Macallan D, Griffin G. Total energy expenditure and physical activity measured with the bicarbonate-urea method in patients with human immunodeficiency virus infection. Clinical Science 1996;91:241-5.

[43] Vancampfort D FJ, Schuch FB, Rosenbaum S, De Hert M, Mugisha J, Probst M, Stubbs B. Physical activity and sedentary behavior in people with bipolar disorder: a systematic review and meta-analysis. Journal of Affective Disorders 2016.

[44] Stubbs B FJ, Berry A, Schuch FB , Rosenbaum S, Gaughran F, Veronesse N , Williams J, Craig T, Yung AR, Vancampfort D How much physical activity do people with schizophrenia engage in? A systematic review, comparative meta-analysis and meta-regression. Schizophrenia Research 2016.

[45] Tudor-Locke C, Bassett Jr DR. How many steps/day are enough? Sports medicine 2004;34:1-8.

[46] Swendeman D, Ingram BL, Rotheram-Borus MJ. Common elements in self-management of HIV and other chronic illnesses: an integrative framework. AIDS care 2009;21:1321-34.

[47] Bauman AE, Reis RS, Sallis JF, Wells JC, Loos RJ, Martin BW, Group LPASW. Correlates of physical activity: why are some people physically active and others not? The Lancet 2012;380:258-71.

[48] Heaton R, Clifford D, Franklin D, Woods S, Ake C, Vaida F, Ellis R, Letendre S, Marcotte T, Atkinson J. HIV-associated neurocognitive disorders persist in the era of potent antiretroviral therapy CHARTER Study. Neurology 2010;75:2087-96.

[49] Ciesla JA, Roberts JE. Meta-analysis of the relationship between HIV infection and risk for depressive disorders. American Journal of Psychiatry 2001;158(5):725-30. 


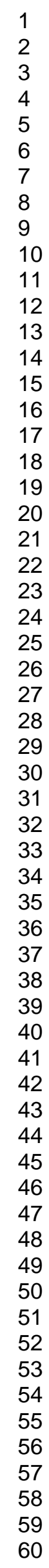

Figure 1 Flow Diagram for the Search Results 
Table 1. Demographical and Clinical Data of the Included Studies

\begin{tabular}{|c|c|c|c|c|c|c|c|c|c|c|c|c|c|c|c|}
\hline Author & $\begin{array}{c}\text { Sample } \\
\text { size }\end{array}$ & Region & Setting & $\begin{array}{c}\text { Assessment } \\
\text { methods }\end{array}$ & $\begin{array}{l}\text { Mean } \\
\text { age }\end{array}$ & $\begin{array}{l}\text { Gender } \\
(\% \text { male })\end{array}$ & $\begin{array}{l}\text { Ethnicity } \\
\text { (\% White) }\end{array}$ & $\begin{array}{c}\text { Employed } \\
(\%)\end{array}$ & BMI & $\begin{array}{l}\text { Infection } \\
\text { years }\end{array}$ & $\begin{array}{c}\text { Diabetes } \\
(\%)\end{array}$ & $\begin{array}{c}\text { Smoker } \\
(\%)\end{array}$ & $\begin{array}{l}\text { Viral } \\
\text { load }\end{array}$ & $\begin{array}{l}\text { CD4+ } \\
\text { current }\end{array}$ & $\begin{array}{c}\text { VO2 } \\
\text { peak/max }\end{array}$ \\
\hline $\begin{array}{l}\text { Rehm } 2016 \text { [19] } \\
\text { Dirajlal-Fargo } 2015\end{array}$ & 50 & 1 & 1 & 2 & 42 & 0 & & & 36.6 & & & & & & \\
\hline $\begin{array}{l}\text { (rosuvastine group) [20] } \\
\text { Dirailal-Fargo } 2015\end{array}$ & 72 & 1 & 2 & 2 & 46 & 81 & & & 27 & 11 & & & & & \\
\hline (placebo group) [20] & 75 & 1 & 2 & 2 & 46 & 76 & & & 27 & 12 & & & & & \\
\hline Fazeli 2015 [21] & 100 & 1 & 3 & 2 & 58.2 & 88 & 82 & & & 18 & 26 & & & 597 & \\
\hline Monroe 2015 [22] & 596 & 1 & 3 & 2 & 51 & 100 & 54 & 55 & 25.3 & & 13 & 30 & & 591 & \\
\hline Hsieh 2014 (men) [23] & 170 & 4 & 2 & 2 & 38.2 & 100 & 0 & & & 3.9 & & & & & \\
\hline Hsieh 2014 (women) [23] & 56 & 4 & 2 & 2 & 39.3 & 0 & 0 & & & 4 & & & & & \\
\hline Jaggers 2014 [25] & 63 & 1 & 1 & 1 & 48 & 49.2 & & & 30.4 & & 14.3 & & & & \\
\hline $\begin{array}{l}\text { Della Justina } 2014 \text { [24] } \\
\text { Ramírez-Marrero } 2014\end{array}$ & 74 & 2 & 2 & 2 & 44.3 & 60.8 & 91.9 & & & & & 46 & 2.2 & 491 & \\
\hline $\begin{array}{l}\text { (HIV Lipo) [26] } \\
\text { Ramírez-Marrero } 2014\end{array}$ & 32 & 1 & 3 & 1 & 50.3 & 40.6 & 0 & & 29 & & 25 & 55 & & & 26.8 \\
\hline (HIV non- Lipo) [26] & 28 & 1 & 3 & 1 & 48.1 & 53.6 & 0 & & 26.4 & & 0 & 19 & & & 32.2 \\
\hline $\begin{array}{l}\text { Raso } 2014[27] \\
\text { Roos } 2014\end{array}$ & 39 & 2 & 2 & 2 & 40.6 & 100 & & & 24.8 & & & & 4.4 & 521 & 34.2 \\
\hline & 42 & 3 & 3 & 1 & 38.7 & 16.7 & & 45.2 & & & 0 & 9.5 & & 340 & \\
\hline (control group) [28] & 42 & 3 & 3 & 1 & 39.4 & 26.2 & & 61.9 & & & 2.4 & 11.9 & 2.8 & 347 & \\
\hline $\begin{array}{l}\text { Edward } 2013 \text { (men) [29] } \\
\text { Edward } 2013 \text { (women) }\end{array}$ & 86 & 3 & 2 & 2 & 41.7 & 100 & & 3.5 & 22.9 & 15.9 & 5.8 & 4.7 & & 253 & \\
\hline & 179 & 3 & 2 & 2 & 37.2 & 0 & & 3.9 & 23.6 & 18 & 6.7 & 0.6 & & 362 & \\
\hline Segatto 2011 [30] & 42 & 2 & 2 & 2 & & 54.8 & & & & & & & & & \\
\hline $\begin{array}{l}\text { Muronya } 2011 \text { (men) [31] } \\
\text { Muronya } 2011 \text { (women) }\end{array}$ & 67 & 3 & 2 & 2 & 43.3 & 100 & & & & & & 1.5 & & & \\
\hline $\begin{array}{l}{[31]} \\
\text { Schuelter-Trevisol } 2010\end{array}$ & 107 & 3 & 2 & 2 & 37 & 0 & & & & & & 0 & & & \\
\hline $\begin{array}{l}\text { (men) [32] } \\
\text { Schuelter-Trevisol } 2010\end{array}$ & 628 & 2 & 2 & 2 & 39.5 & 100 & & & 24.4 & 5.2 & & 66 & & 368 & \\
\hline (women) [32] & 612 & 2 & 2 & 2 & 37.7 & 0 & & & 25.4 & 4.6 & & 60.8 & & 383 & \\
\hline Fillipas 2010 [33] & 30 & 6 & 1 & 1 & 53.2 & 100 & & & 25.6 & 13.4 & & & & & \\
\hline Allard 2008 [34] & 65 & 1 & & 2 & 47 & 100 & & & 26.5 & 11.4 & & 26.2 & & 487 & \\
\hline Fillipas 2008 [35] & 191 & 6 & 1 & 2 & 43.9 & 92.7 & & & & & & & & & \\
\hline
\end{tabular}




\section{Page 23 of 30}

Disability and Rehabilitation

Table 1. Continued

\begin{tabular}{|c|c|c|c|c|c|c|c|c|c|c|c|c|c|c|c|}
\hline Author & $\begin{array}{c}\text { Sample } \\
\text { size }\end{array}$ & Region & Setting & $\begin{array}{c}\text { Assessment } \\
\text { method }\end{array}$ & $\begin{array}{c}\text { Mean } \\
\text { age }\end{array}$ & $\begin{array}{c}\text { Gender } \\
(\% \text { male })\end{array}$ & $\begin{array}{l}\text { Ethnicity } \\
\text { (\% White) }\end{array}$ & $\begin{array}{c}\text { Employed } \\
(\%)\end{array}$ & BMI & $\begin{array}{c}\text { Infection } \\
\text { years }\end{array}$ & $\begin{array}{c}\text { Diabetes } \\
(\%)\end{array}$ & $\begin{array}{c}\text { Smoker } \\
(\%)\end{array}$ & $\begin{array}{l}\text { Viral } \\
\text { load }\end{array}$ & $\begin{array}{c}\text { CD4+ } \\
\text { current }\end{array}$ & $\begin{array}{c}\text { VO2 } \\
\text { peak/max }\end{array}$ \\
\hline \multirow{5}{*}{ 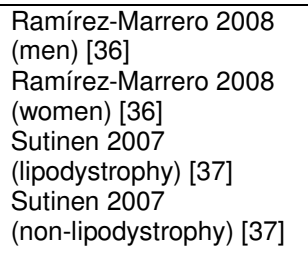 } & 35 & 1 & 3 & 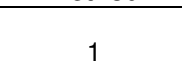 & 45.9 & 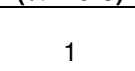 & & & 25.6 & & & & & & \\
\hline & 23 & 1 & 3 & 1 & 47.3 & 0 & & & 28.7 & & & & & & \\
\hline & & & & & & & & & & & & & & & \\
\hline & 30 & 5 & 2 & 2 & 43 & 83 & & & & 8.2 & & & 1.87 & 572 & \\
\hline & 13 & 5 & 2 & 2 & 39 & 69 & & & & 8.6 & & & 1.65 & 516 & \\
\hline de Lima Eidam 2006 [38] & 11 & 2 & 2 & 2 & 37 & 61.3 & & 47.8 & & & & & & 345 & \\
\hline Clingerman 2003 [41] & 78 & 1 & 3 & 2 & 40.4 & 90 & & 61.5 & 24.2 & & & & & 386 & \\
\hline \multirow{3}{*}{$\begin{array}{l}\text { Bopp 2004 [39] } \\
\text { Ramírez-Marrero } 2004 \\
\text { (men) [40] } \\
\text { Ramírez-Marrero } 2004 \\
\text { (women) [40] }\end{array}$} & 66 & 1 & 3 & 1 & 39 & 100 & 5 & & & & & & 3.8 & 412 & \\
\hline & 43 & 1 & 3 & 2 & 40.4 & 100 & & & & & & & & 343 & \\
\hline & 25 & 1 & 3 & 2 & 40.4 & 0 & & & & & & & & 256 & \\
\hline Paton 1996 [42] & 10 & 5 & & 2 & 33.5 & 100 & & & & & & & & & \\
\hline
\end{tabular}


Table 2. Physical Activity Outcomes of the Included Studies

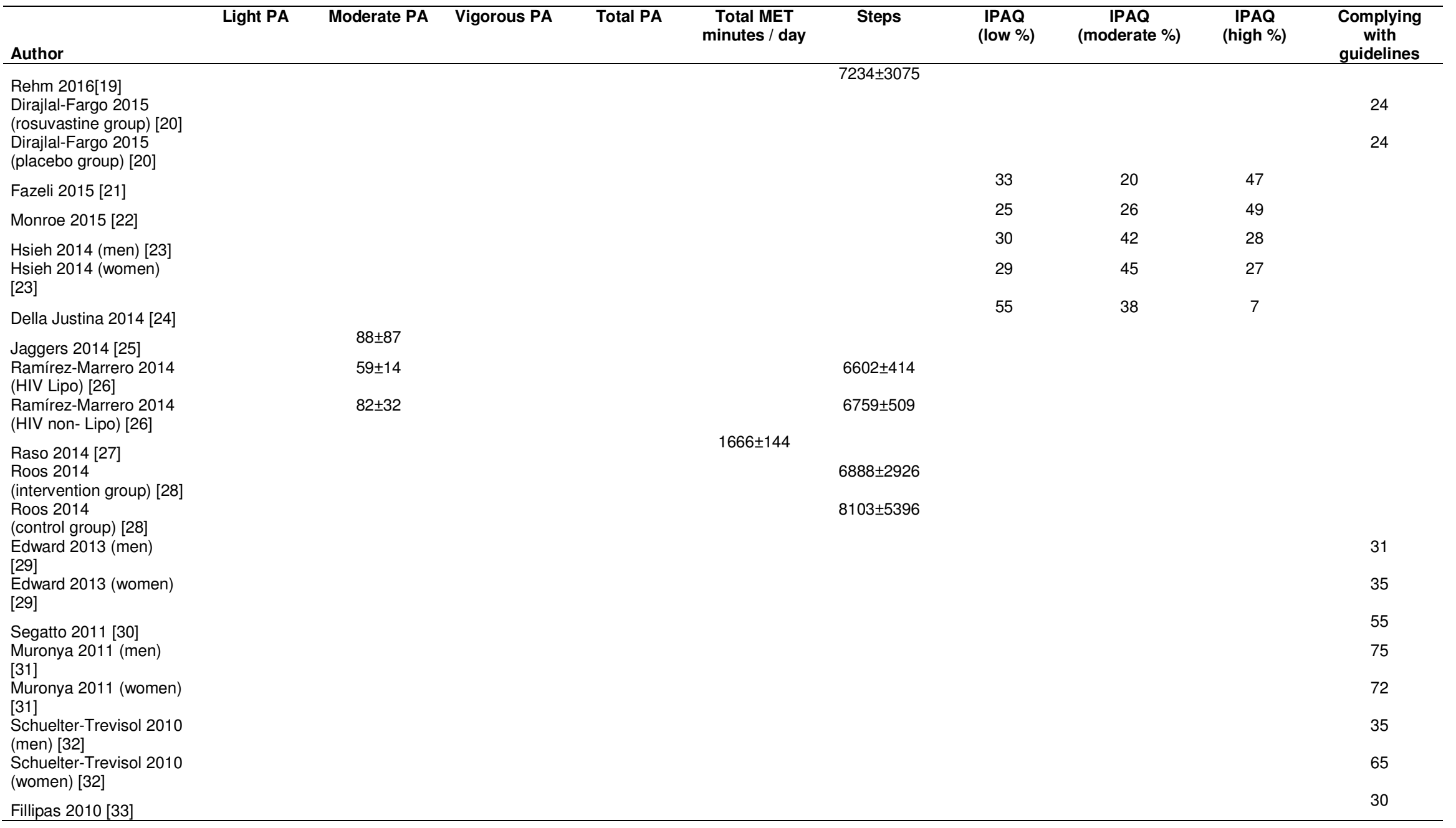




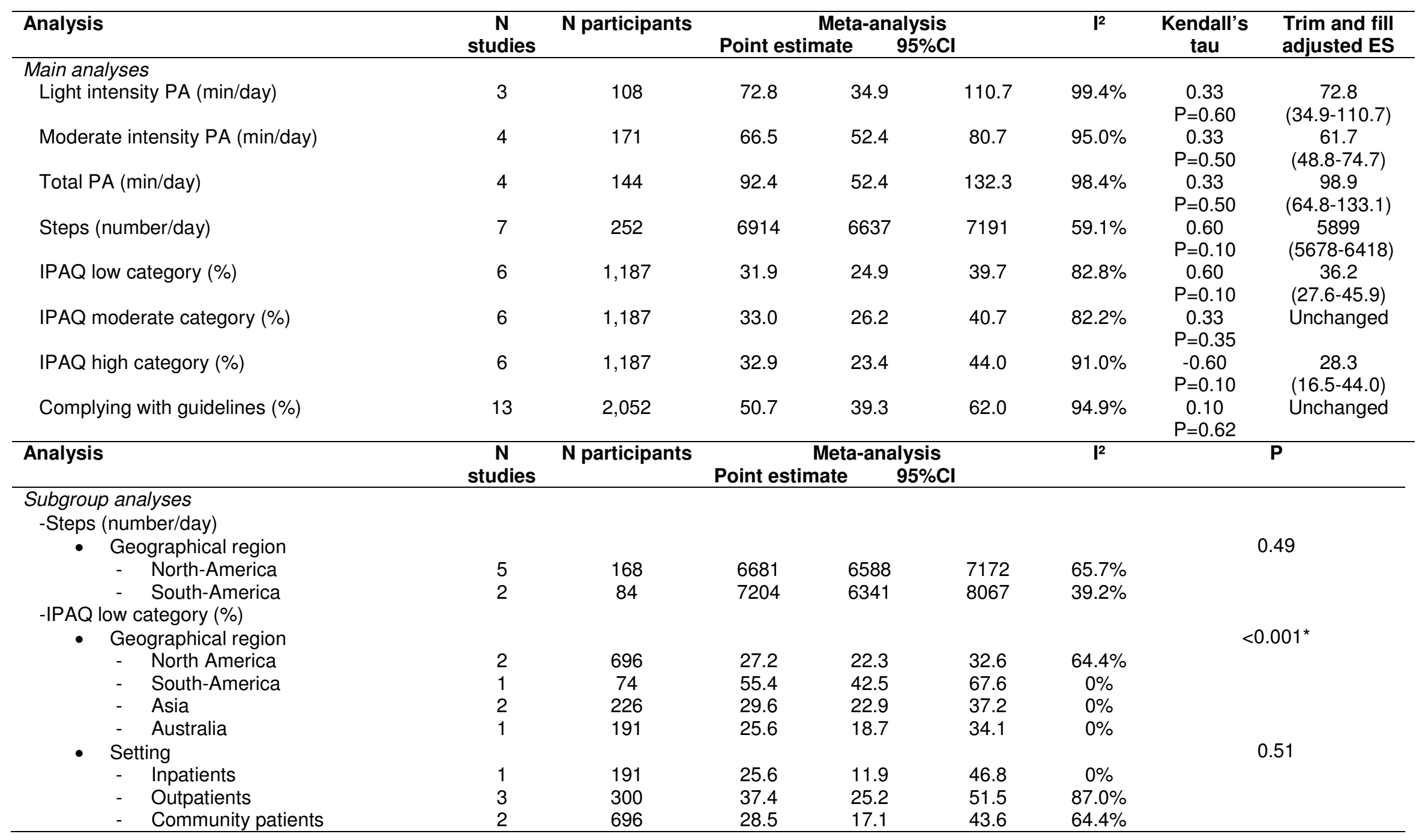

Table 3. Continued 


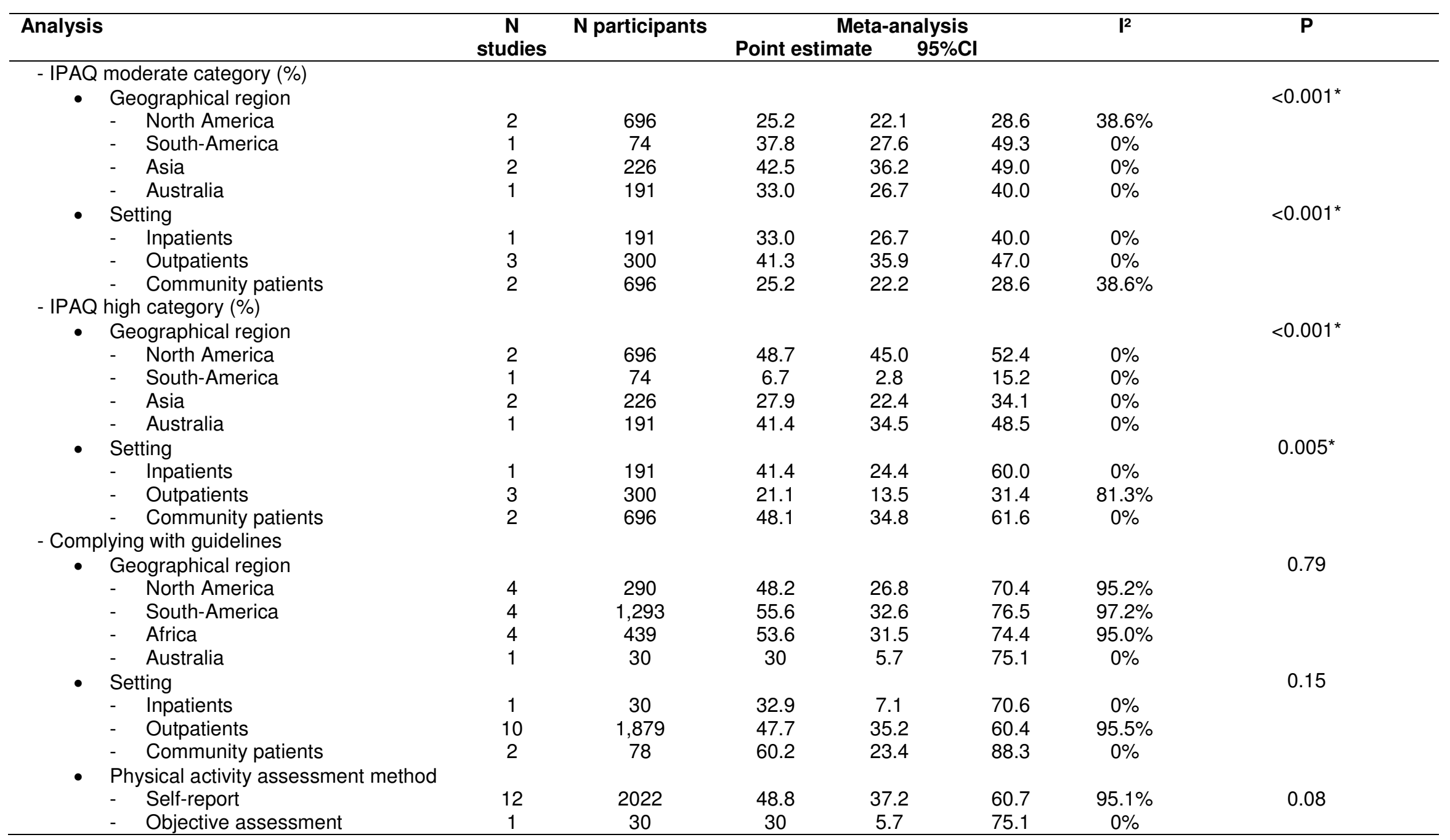

$\mathrm{ES}=$ Effect size, $\mathrm{PA}=$ physical activity, IPAQ= International Physical Activity Questionnaire, ${ }^{*}$ Significant when $\mathrm{P}<0.05$.. 


\begin{tabular}{|c|c|c|c|c|c|c|c|}
\hline \multirow{2}{*}{$\begin{array}{l}\text { Moderator } \\
\text { Steps (number/day) }\end{array}$} & \multirow{2}{*}{$\begin{array}{c}\mathbf{N} \\
\text { studies }\end{array}$} & \multirow[t]{2}{*}{$\boldsymbol{\beta}$} & \multirow[t]{2}{*}{ SE } & \multicolumn{2}{|c|}{$95 \% \mathrm{Cl}$} & \multirow[t]{2}{*}{ P-value } & \multirow[t]{2}{*}{$\mathbf{R}^{2}$} \\
\hline & & & & & & & \\
\hline Age (years) & 7 & -66.7 & 34.1 & -133.4 & 0.22 & 0.049 & 0.57 \\
\hline Gender (\% male) & 7 & -225.5 & 590.4 & -1382.8 & 931.6 & 0.70 & 0 \\
\hline $\mathrm{BMI}$ & 5 & 16.3 & 57.7 & -96.8 & 129.4 & 0.78 & 0 \\
\hline Diabetes (\%) & 4 & -1019.0 & 1358.8 & -3618.4 & 1643.4 & 0.45 & 0 \\
\hline Smoking (\%) & 4 & -681.4 & 687.4 & -2028.6 & 665.8 & 0.32 & 0 \\
\hline \multicolumn{8}{|l|}{ IPAQ low category (\%) } \\
\hline Age (years) & 6 & -0.002 & 0.028 & -0.06 & 0.05 & 0.94 & 0 \\
\hline Gender (\% male) & 6 & -0.33 & 0.52 & -1.35 & 0.69 & 0.53 & 0.05 \\
\hline Ethnicity (\% White) & 5 & 0.70 & 0.59 & -0.46 & 1.86 & 0.24 & 0 \\
\hline \multicolumn{8}{|l|}{ IPAQ moderate category (\%) } \\
\hline Age (years) & 6 & -0.05 & 0.01 & -0.08 & -0.03 & $<0.001^{*}$ & 1.0 \\
\hline Gender (\% male) & 6 & -0.61 & 0.48 & -1.56 & 0.34 & 0.21 & 0.10 \\
\hline Ethnicity (\% White) & 5 & -0.75 & 0.46 & -1.66 & 0.16 & 0.11 & 0.39 \\
\hline \multicolumn{8}{|l|}{ IPAQ high category (\%) } \\
\hline Age (years) & 6 & 0.06 & 0.03 & -0.001 & 0.11 & 0.054 & 0.35 \\
\hline Gender (\% male) & 6 & 0.94 & 0.66 & -0.36 & 2.24 & 0.15 & 0.12 \\
\hline Ethnicity (\% White) & 5 & -0.25 & 0.86 & -1.94 & 1.44 & 0.77 & 0 \\
\hline \multicolumn{8}{|l|}{ Complying with guidelines (\%) } \\
\hline Age (years) & 13 & -0.06 & 0.05 & -0.16 & 0.05 & 0.28 & 0.01 \\
\hline Gender (\% male) & 13 & -0.36 & 0.58 & -1.49 & 0.78 & 0.54 & 0.01 \\
\hline $\begin{array}{l}\text { Assessment method } \\
\text { (obiective method as reference) }\end{array}$ & 13 & 0.80 & 0.89 & -0.95 & 2.56 & 0.37 & 0 \\
\hline
\end{tabular}

$\mathrm{SE}=$ standard error, BMI=body mass index, IPAQ= International Physical Activity Questionnaire, ${ }^{*}$ Significant when $\mathrm{P}<0.05$. 
Figure 1 Flow Diagram for the Search Results
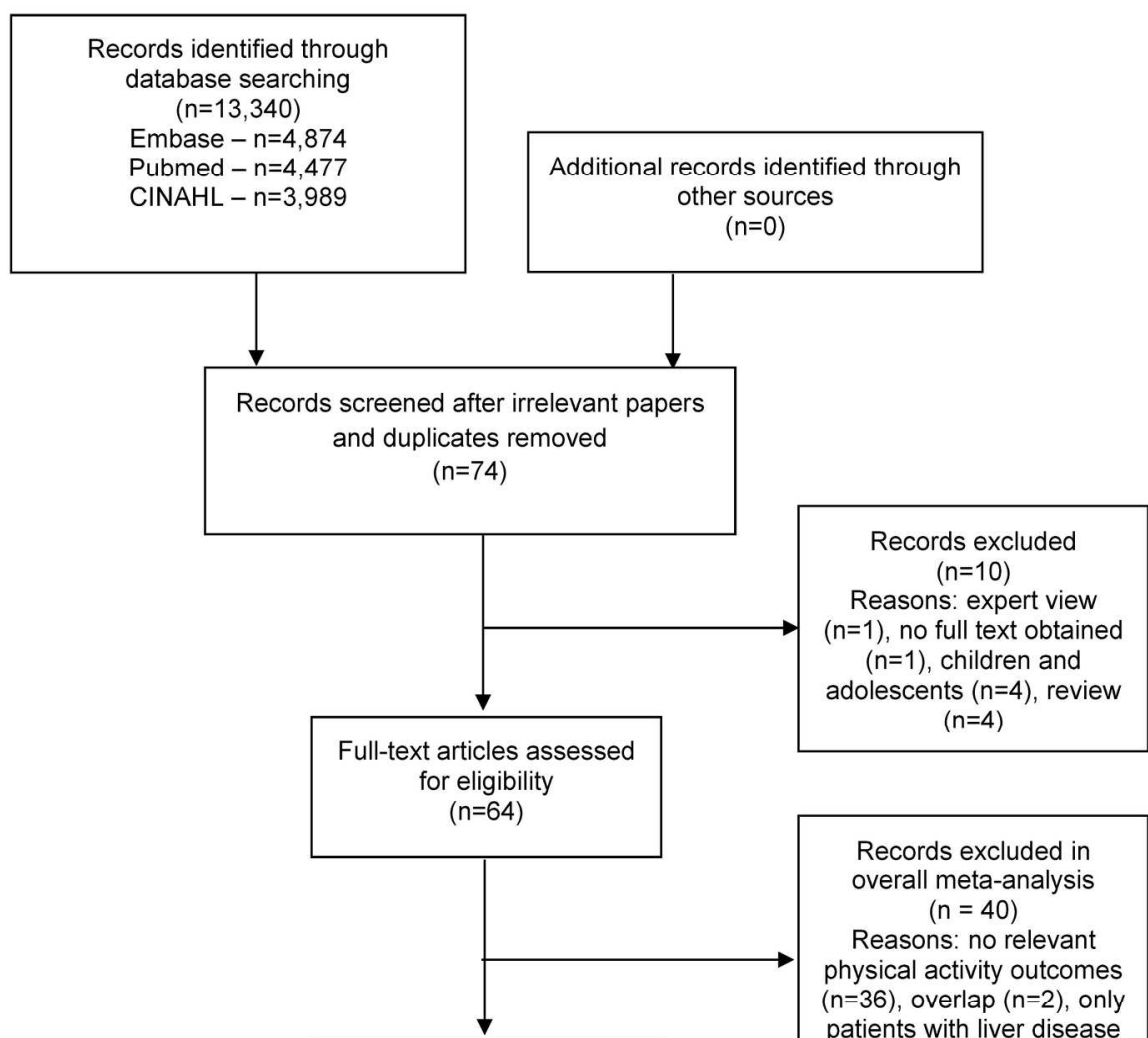

Studies included in main quantitative synthesis (overall meta-analysis) $(n=24)$

Records excluded in overall meta-analysis $(n=40)$

Reasons: no relevant physical activity outcomes $(n-36)$, overlap $(n-2)$, only patients with liver disease $(n=1)$, only drug users $(n=1)$

Figure 1 Flow Diagram for the Search Results $187 \times 198 \mathrm{~mm}(300 \times 300 \mathrm{DPI})$ 